\title{
MODELING AND IDENTIFICATION OF BALL SCREW FEED DRIVE SYSTEMS
}

\author{
M. A. Asy \\ Associate Professor, Production \\ Engineering and Mechanical \\ Design Department, Faculty of \\ Engineering, Menoufia University, \\ Shebin El Kom, Egypt.
}

\author{
S. A. Hassan \\ Lecturer, Production \\ Engineering and Mechanical \\ Design Department, Faculty of \\ Engineering, Menoufia University, \\ Shebin El Kom, Egypt.
}

\author{
M. H. Elsaroukh \\ Demonstrator, Production \\ Engineering and Mechanical \\ Design Department, Faculty of \\ Engineering, Menoufia University, \\ Shebin El Kom, Egypt.
}

\begin{abstract}
In this paper, the ball screw feed drive system is simulated and it's frequency response is studied. Various parameters effect on the dynamic behavior of the ball screw system have been investigated. Ball screw feed drive system is used in high speed machine tools due to their high efficiency. Estimation of the dynamic behavior of ball screw feed drive mechanism is very important in the industrial processes in order to get high demand for precision and accuracy in machine tools. Optimizing the drive operation can provide significant cost savings. A four degree of freedom system, lumped parameter model is used for modeling a single axis ball screw feed drive system and use it to study and analyze vibrations in this model. The mathematical modeling provides an important information about frequency response when applying different levels of table mass, stiffness of the nut, axial stiffness of the ball screw shaft and torsional stiffness of the ball screw on the system, to describe the effects of these parameters on the system dynamic behavior. The study of dynamic response of ball screw feed drive system provides a better performance control and better understanding of ball screw dynamics.
\end{abstract}

Keywords - Ball screw, Feed drive, Machine tool, Modeling, Vibrations

\section{NOMENCLATURE}

$\mathrm{J}_{\mathrm{m}}=$ inertia moment of the motor (kg.m2)

$\mathrm{J}_{\mathrm{s}}=$ inertia moment of the ball screw (kg.m2)

$\mathrm{M}_{\mathrm{s}}=$ the mass of ball screw $(\mathrm{kg})$

$\mathrm{M}_{\mathrm{t}}=$ the mass of working table $(\mathrm{kg})$

$\mathrm{Q}_{\mathrm{m}}=$ rotational viscous damping coefficient of the motor (N.s/m)

$\mathrm{Q}_{\mathrm{b}}=$ rotational viscous damping coefficient of the support bearing of ball screw (N.s/m)

$\mathrm{C}_{\mathrm{b}}=$ viscous damping coefficient of the supporting bearing of the ball screw (N.s/m)

$\mathrm{C}_{\mathrm{t}}=$ viscous damping coefficient of the guide way of the working table (N.s/m)
$\mathrm{K}_{\mathrm{n}}=$ stiffness of the nut $(\mathrm{N} / \mathrm{m})$

$\mathrm{K}_{\mathrm{t}}=$ torsional stiffness of the ball screw shaft (N.m/rad)

$\mathrm{K}_{\mathrm{a}}=$ equivalent axial stiffness of ball screw shaft (N/m)

$\mathrm{R}=$ angle conversion axial displacement of the constant

"angle conversion from rotational to axial displacement"

$\mathrm{T}=$ motor torque (N.m)

$\mathrm{X}_{\mathrm{s}}=$ axial displacement of the ball screw shaft (m)

$\mathrm{X}_{\mathrm{t}}=$ axial displacement of the working table (m)

$\theta_{\mathrm{m}}=$ rotation angle of the motor $(\mathrm{rad})$

$\theta_{\mathrm{s}}=$ rotation angle of the ball screw shaft (rad)

\section{INTRODUCTION}

The quality and productivity of machine tools production depend on their performance; the speed and positioning accuracy of feed drive system. The main purpose of its function is to move the cutting tool and work piece to the desired location and positioning the working parts of machine tools [1]. Comparing to other traditional linear actuators, Ball screw feed drive system is widely used in advanced industrial machinery due to their high efficiency and high positioning accuracy. It translates the rotational motion of a motor drive into a linear motion. Vibrations of ball screw feed drive system exist because of friction and interaction force between the balls, screw and nut. The values of these forces change with different position of the orbital system [2]. Most of the previous researches are concerned with reducing the existing vibrations and studying the variables that affect them. Many parameters such as table mass, stiffness of the ball nut, axial stiffness of the ball screw shaft and torsional stiffness of the ball screw have high effect on the frequency response of the system. So using mathematical model provide a better way to study these parameters [3, 4 and 5].

The vibration of ball screw feed drive system may be characterized by more than one mode of motion. It can be characterized by lateral, axial and torsional [6 and 7]. In this paper concerned with the hybrid modeling of a single axis ball screw feed drive system and consider the system consists of four degrees of freedom [4 and 7]. The mathematical model 


\section{International Journal of Engineering Applied Sciences and Technology, 2020 \\ Vol. 5, Issue 8, ISSN No. 2455-2143, Pages 28-35 \\ Published Online December 2020 in IJEAST (http://www.ijeast.com)}

estimates the quantitative dynamic behavior of the ball screw feed drive system. By substituting the measured parameters of the system on the mathematical model, we can study the effect of each parameter on the frequency response of ball screw feed drive system.

\section{MATHEMATICAL MODELLING}

\section{A. Modeling of Feed Drive System -}

In general, ball screw feed drive system consists of motor, coupler, screw shaft, ball screw nut, balls, support bearing and work table. This investigation interested with studying the modeling and vibration of a single axis ball screw feed drive system as shown in Fig. (1).

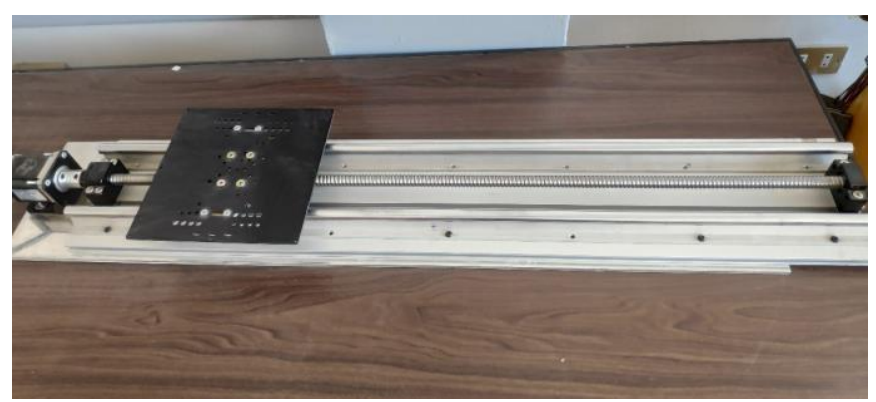

Fig. (1): A single axis ball screw feed drive system.

In this system, the authors try to make a model of the ball screw feed drive system by transforming the physical representation of it to equations and using these equations to simulate the system. A single axis ball screw feed drive system can be represented by a four displacements which consist of both axial and rotational displacements, Fig. (2) shows the schematic diagram of a ball screw feed drive system [3].

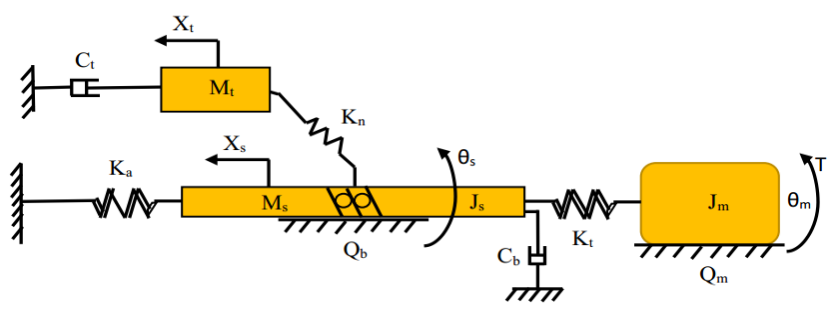

Fig. (2): Schematic diagram of a ball screw feed drive system.
The equations of a general multi-degree-of-freedom system are derived using the potential and kinetic energies and use them in deriving the equations of motion.

The kinetic energy of the system, T, can be expressed as

$$
T=\frac{1}{2} J_{m} \theta_{m}{ }^{2}+\frac{1}{2} J_{s} \theta_{s}{ }^{2}+\frac{1}{2} M_{s} X_{s}{ }^{2}+\frac{1}{2} M_{t} X_{t}{ }^{2}
$$

The mass matrix can be expressed as

$$
\left[M_{\text {model }}\right]=\left[\begin{array}{cccc}
J_{\mathrm{m}} & 0 & 0 & 0 \\
0 & J_{s} & 0 & 0 \\
0 & 0 & M_{s} & 0 \\
0 & 0 & 0 & M_{\mathrm{t}}
\end{array}\right]
$$

The dissipated energy of the system which refer to the energy that is lost from the system"D", can be expressed as

$$
D=\frac{1}{2} Q_{m} \theta_{m}{ }^{2}+\frac{1}{2} Q_{b} \theta_{s}{ }^{2}+\frac{1}{2} C_{b} X_{s}{ }^{2}+\frac{1}{2} C_{t} X_{t}{ }^{2}
$$

The damping matrix can be expressed as

$$
\left[C_{\text {model }}\right]=\left[\begin{array}{cccc}
Q_{m} & 0 & 0 & 0 \\
0 & Q_{b} & 0 & 0 \\
0 & 0 & C_{b} & 0 \\
0 & 0 & 0 & C_{t}
\end{array}\right]
$$

The potential energy of the system, V, due to the strain energy of the springs, can be expressed as

$$
\begin{gathered}
V=\frac{1}{2} K_{\mathrm{t}}\left(\theta_{\mathrm{m}}-\theta_{s}\right)^{2}+\frac{1}{2} K_{\mathrm{a}} X_{s}{ }^{2}+\frac{1}{2} K_{\mathrm{n}}\left(R \theta_{s}+X_{s}-X_{\mathrm{t}}\right)^{2} \\
V=\frac{1}{2} K_{\mathrm{t}} \theta_{\mathrm{m}}{ }^{2}+\frac{1}{2} K_{\mathrm{t}} \theta_{s}{ }^{2}-\frac{1}{2} \times 2 K_{\mathrm{t}} \theta_{\mathrm{m}} \theta_{s} \\
+\frac{1}{2} K_{\mathrm{a}} X_{g}{ }^{2}+\frac{1}{2} K_{\mathrm{n}}\left(R^{2} \theta_{s}{ }^{2}\right. \\
+R \theta_{g} X_{s}-R \theta_{s} X_{\mathrm{t}}+R \theta_{s} X_{s}+X_{s}{ }^{2} \\
\left.-X_{g} X_{\mathrm{t}}-R \theta_{g} X_{\mathrm{t}}-X_{g} X_{\mathrm{t}}+X_{\mathrm{t}}{ }^{2}\right) \\
V=\frac{1}{2} K_{\mathrm{t}} \theta_{m}{ }^{2}+\frac{1}{2} K_{\mathrm{t}} \theta_{s}{ }^{2}-\frac{1}{2} \times 2 K_{\mathrm{t}} \theta_{m} \theta_{s} \\
+\frac{1}{2} K_{a} X_{s}{ }^{2}+\frac{1}{2} K_{n} R^{2} \theta_{s}{ }^{2}+\frac{1}{2} K_{n} R \theta_{g} X_{s}
\end{gathered}
$$


Published Online December 2020 in IJEAST (http://www.ijeast.com)

$$
\begin{aligned}
& -\frac{1}{2} K_{n} R \theta_{s} X_{\mathrm{t}}+\frac{1}{2} K_{n} R \theta_{s} X_{g}+\frac{1}{2} K_{n} X_{g}{ }^{2} \\
& -\frac{1}{2} K_{n} X_{g} X_{\mathrm{t}}-\frac{1}{2} K_{n} R \theta_{s} X_{\mathrm{t}}-\frac{1}{2} K_{n} X_{g} X_{\mathrm{t}}+\frac{1}{2} K_{n} X_{\mathrm{t}}^{2} \\
& V=\frac{1}{2} K_{\mathrm{t}} \theta_{m}{ }^{2}+\frac{1}{2}\left(K_{\mathrm{t}}+K_{n 1} R^{2}\right) \theta_{s}{ }^{2}-\frac{1}{2} \times 2 K_{\mathrm{t}} \theta_{m} \theta_{s} \\
& +\frac{1}{2}\left(K_{\alpha_{a}}+K_{n}\right) X_{s}^{2}+\frac{1}{2}\left(K_{n} R+K_{n} R\right) \theta_{s} X_{s} \\
& -\frac{1}{2}\left(K_{n} R+K_{n} R\right) \theta_{g} X_{\mathrm{t}}-\frac{1}{2}\left(K_{n}+K_{n}\right) X_{g} X_{\mathrm{t}}+\frac{1}{2} K_{n} X_{\mathrm{t}}^{2} \\
& V=\frac{1}{2} K_{\mathrm{t}} \theta_{m}^{2}+\frac{1}{2}\left(K_{\mathrm{t}}+K_{n} R^{2}\right) \theta_{s}^{2} \\
& -\frac{1}{2} \times 2 K_{t} \theta_{m} \theta_{s}+\frac{1}{2}\left(K_{L}+K_{n}\right) X_{s}^{2} \\
& +\frac{1}{2} \times 2 K_{n} R \theta_{s} X_{s}-\frac{1}{2} \times 2 K_{n} R \theta_{s} X_{\mathrm{t}} \\
& -\frac{1}{2} \times 2 K_{n} X_{s} X_{\mathrm{t}}+\frac{1}{2} K_{n} X_{\mathrm{t}}^{2}
\end{aligned}
$$

$$
\begin{aligned}
& +\left[\begin{array}{cccc}
K_{t} & -K_{t} & 0 & 0 \\
-K_{t} & K_{t}+K_{n} R^{2} & K_{n} R & -K_{n} R \\
0 & K_{n} R & K_{a}+K_{n} & -K_{n} \\
0 & -K_{n} R & -K_{n} & K_{n}
\end{array}\right]\left[\begin{array}{c}
\theta_{m} \\
\theta_{s} \\
X_{s} \\
X_{t}
\end{array}\right] \\
& =\left[\begin{array}{l}
T \\
0 \\
0 \\
0
\end{array}\right]
\end{aligned}
$$

This mathematical model is used to make simulation of ball screw feed drive system and study the effect of various parameters in the dynamic behavior of the system.

\section{$B$. Simulation of Feed Drive System -}

The four states in the above matrix equation are $\theta_{\mathrm{m}}$ refers to rotation displacement of motor, $\theta_{\mathrm{s}}$ refers to rotation displacement of the ball screw shaft, $X_{s}$ refers to axial

\begin{tabular}{|c|c|}
\hline $\begin{array}{l}\text { Parameter of the } \\
\text { component }\end{array}$ & Value \\
\hline $\mathbf{J}_{\mathrm{m}}\left(\mathbf{k g} \cdot \mathbf{m}^{2}\right)$ & $4.8 \times 10^{-5}$ \\
\hline $\mathbf{J}_{\mathrm{s}}\left(\mathbf{k g} \cdot \mathbf{m}^{2}\right)$ & $0.495 \times 10^{-4}$ \\
\hline$M_{s}(\mathbf{k g})$ & 1.8 \\
\hline $\mathbf{M}_{\mathbf{t}}(\mathbf{k g})$ & 0.373 \\
\hline $\mathbf{Q}_{\mathrm{m}}(\mathbf{N} . \mathrm{s} / \mathrm{m})$ & $\mathbf{0}$ \\
\hline$Q_{b}(\mathbf{N} . s / m)$ & 0 \\
\hline $\mathrm{C}_{b}(\mathbf{N} . \mathbf{s} / \mathbf{m})$ & 0 \\
\hline $\begin{array}{l}\text { Parameter of the } \\
\text { component }\end{array}$ & Value \\
\hline $\mathrm{C}_{\mathrm{t}}(\mathrm{N} . \mathrm{s} / \mathrm{m})$ & $\mathbf{0}$ \\
\hline$K_{n}(N / m)$ & $0.4689 \times 10^{7}$ \\
\hline
\end{tabular}
displacement of the ball screw shaft and $X_{t}$ refers to axial displacement of the working table. The values and states of this model are defined in table (1).

Table -1 . The values of experimental set up used in numerical simulation

The stiffness matrix can be expressed as

$$
\left[K_{\text {model }}\right]=\left[\begin{array}{cccc}
K_{\mathrm{t}} & -K_{\mathrm{t}} & 0 & 0 \\
-K_{\mathrm{t}} & K_{\mathrm{t}}+K_{n} R^{2} & K_{n} R & -K_{n} R \\
0 & K_{n} R & K_{a}+K_{n} & -K_{n} \\
0 & -K_{n} R & -K_{n} & K_{n}
\end{array}\right]
$$

The general form of the equations of motion is formulated in matrix form as:

$$
\begin{gathered}
{\left[\begin{array}{cccc}
J_{m} & 0 & 0 & 0 \\
0 & J_{s} & 0 & 0 \\
0 & 0 & M_{s} & 0 \\
0 & 0 & 0 & M_{t}
\end{array}\right] \times\left[\begin{array}{c}
\theta_{m}^{-} \\
\theta_{s}^{--} \\
X_{s}^{-} \\
X_{t}^{--}
\end{array}\right]} \\
+\left[\begin{array}{cccc}
Q_{m} & 0 & 0 & 0 \\
0 & Q_{b} & 0 & 0 \\
0 & 0 & C_{b} & 0 \\
0 & 0 & 0 & C_{t}
\end{array}\right]\left[\begin{array}{c}
\theta_{m}^{-} \\
\theta_{s}^{-} \\
X_{s}^{-} \\
X_{t}^{-}
\end{array}\right]
\end{gathered}
$$


International Journal of Engineering Applied Sciences and Technology, 2020

Vol. 5, Issue 8, ISSN No. 2455-2143, Pages 28-35

Published Online December 2020 in IJEAST (http://www.ijeast.com)

\begin{tabular}{|c|c|}
\hline$K_{\mathbf{t}}(\mathbf{N} . \mathbf{m} / \mathbf{r a d})$ & 496.7 \\
\hline$K_{\mathrm{a}}(\mathbf{N} / \mathbf{m})$ & $0.3619 \times 10^{8}$ \\
\hline$R$ & 0.0025 \\
\hline T(N.m) & 1.3 \\
\hline
\end{tabular}

Bode diagram of the dynamic system based on different values of table mass is shown in Fig. (4). The three different values of table masses are $110 \%, 100 \%$ and $90 \%$ of the rated table mass which its value equal to $0.373 \mathrm{~kg}$ as shown in table (1). So the three different masses are 0.4103 $\mathrm{kg}, 0.373 \mathrm{~kg}$ and $0.3357 \mathrm{~kg}$ respectively.

\section{RESULTS}

The equation of motion of the lumped parameters of ball screw feed drive system can be used to represent the transient response of the system. The motor torque represent the force applied to the system. The natural frequencies of the model are $6.1035 \times 10^{-5} \mathrm{rad} / \mathrm{sec}, 3.1636 \times 10^{3} \mathrm{rad} / \mathrm{sec}$, $4.5115 \times 10^{3} \mathrm{rad} / \mathrm{sec}$ and $5.0886 \times 10^{3} \mathrm{rad} / \mathrm{sec}$. the mode shape vectors $\mathrm{V} 1, \mathrm{~V} 2, \mathrm{~V} 3$, and $\mathrm{V} 4$ of the model as shown in table (2).

Table -2. Shows the various mode shape for " $\theta_{\mathrm{m}}, \theta_{\mathrm{s}}, X_{\mathrm{s}}$ and

\begin{tabular}{|c|r|r|r|}
\hline $\begin{array}{c}\text { The first } \\
\text { mode }\end{array}$ & $\begin{array}{c}\text { The second } \\
\text { mode }\end{array}$ & $\begin{array}{c}\text { The third } \\
\text { mode }\end{array}$ & $\begin{array}{c}\text { The fourth } \\
\text { mode }\end{array}$ \\
$\mathrm{V} 1=0.7071$ & $\mathrm{~V} 2=-0.9980$ & $\mathrm{~V} 3=-0.7189$ & $\mathrm{~V} 4=-0.5540$ \\
0.7071 & -0.0327 & 0.6951 & 0.8323 \\
0.0000 & 0.0109 & -0.0018 & 0.0145 \\
0.0018 & 0.0531 & 0.0001 & -0.0157 \\
\hline
\end{tabular}

The bode diagram which involves the graphical representation of the frequency responses of a single axis ball screw feed drive system is shown in Fig. (3).

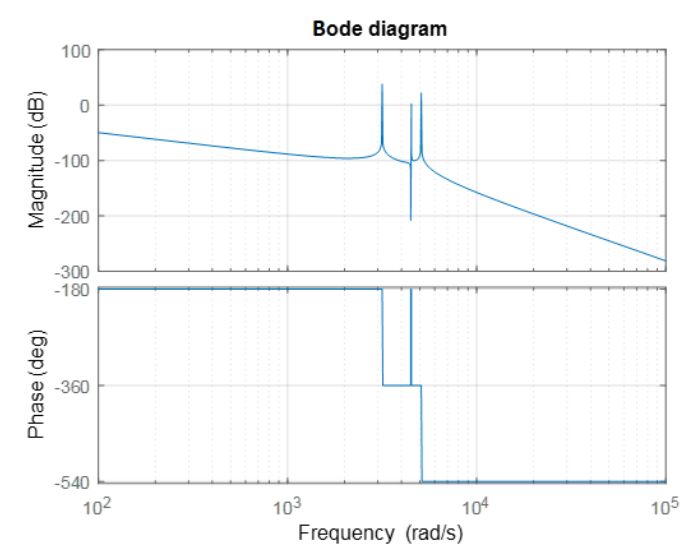

Fig. (3): Bode diagram of a ball screw feed drive system

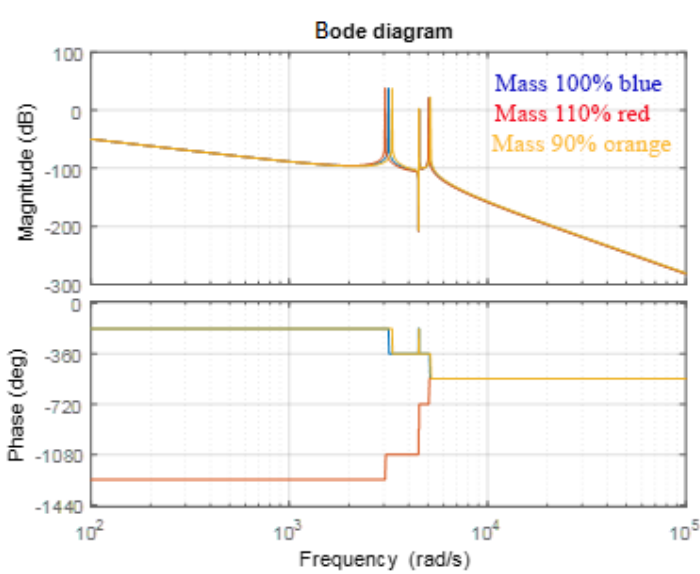

Fig. (4): Bode diagram of table mass

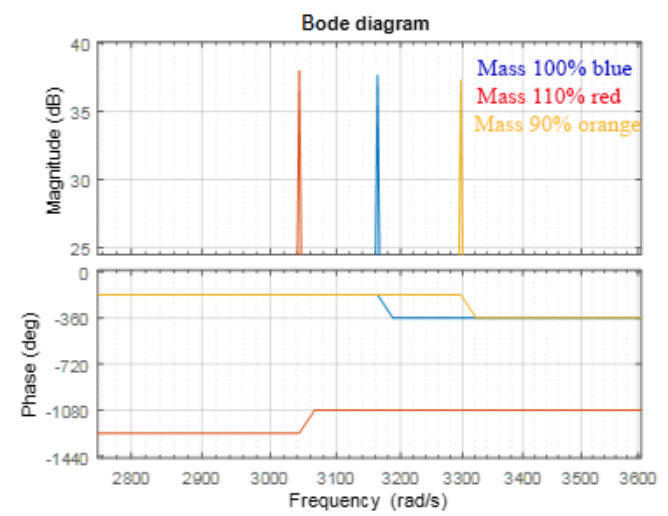

Fig. (5): The enlargement of the second mode of the Bode diagram shown in Fig. (4) 

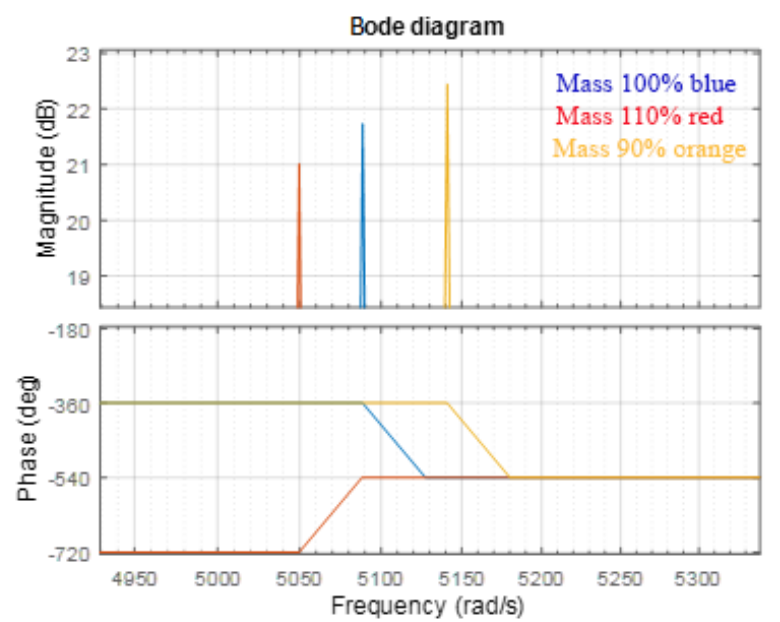

Fig. (6): The enlargement of the fourth mode of the Bode diagram shown in Fig. (4)

The bode diagram of the dynamic system based on different values of stiffness of the nut is shown in Fig. (7). The three different values of stiffness of the ball nut are $110 \%, 100 \%$ and $90 \%$ of the value of the rated stiffness of the nut which its value equal to $0.4689 \times 10^{7} \mathrm{~N} / \mathrm{m}$ as shown in table (1). So the three different stiffness of nut are $0.51579 \times$ $10^{7} \mathrm{~N} / \mathrm{m}, \quad 0.4689 \times 10^{7} \mathrm{~N} / \mathrm{m}$ and $0.42201 \times 10^{7} \mathrm{~N} / \mathrm{m}$ respectively.

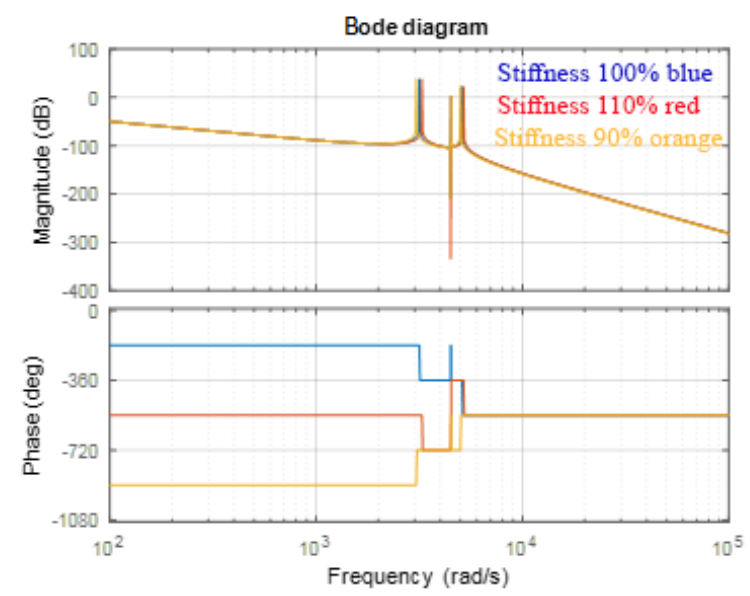

Fig. (7): Bode diagram of stiffness of the nut

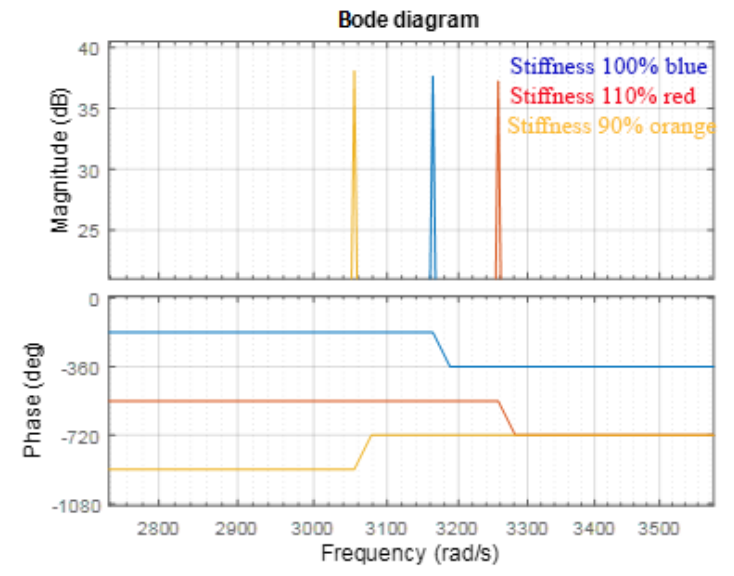

Fig. (8): The enlargement of the second mode of the Bode diagram in Fig. (7)

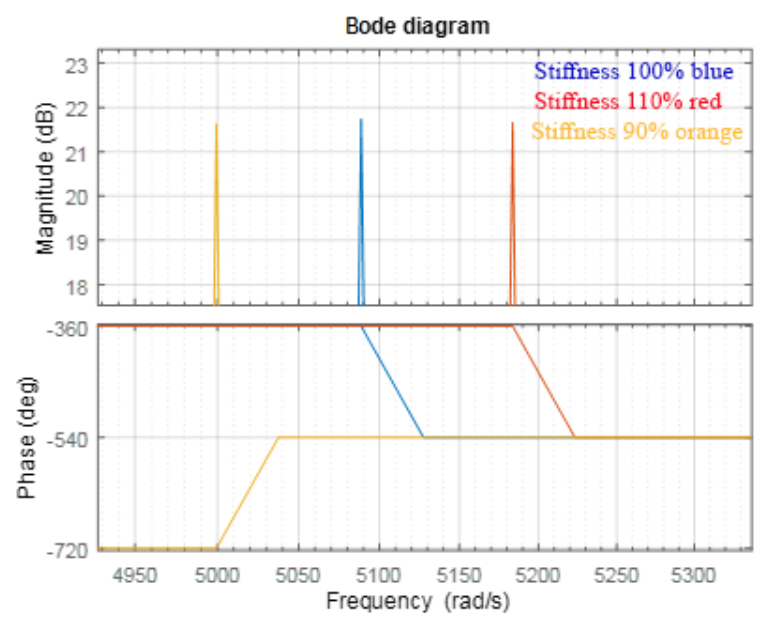

Fig. (9): The enlargement of the fourth mode of the Bode diagram in Fig. (7)

The bode diagram of the dynamic system based on different values of axial stiffness of the ball screw shaft is shown in Fig. (10). The three different values of axial stiffness of the ball screw shaft are $110 \%, 100 \%$ and $90 \%$ of the value of the rated axial stiffness of the ball screw shaft which its value equal to $0.3619 \times 10^{8} \mathrm{~N} / \mathrm{m}$ as shown in table (1). So the three different axial stiffness of the ball screw shaft are $0.39809 \times 10^{8} \mathrm{~N} / \mathrm{m}, 0.3619 \times 10^{8} \mathrm{~N} / \mathrm{m}$ and $0.32571 \times$ $10^{8} \mathrm{~N} / \mathrm{m}$ respectively. 


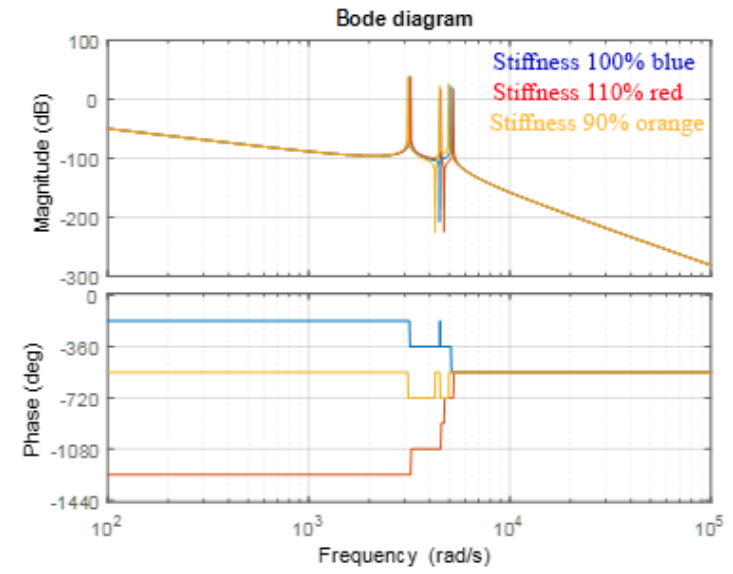

Fig. (10): Bode diagram of axial stiffness of the ball screw shaft

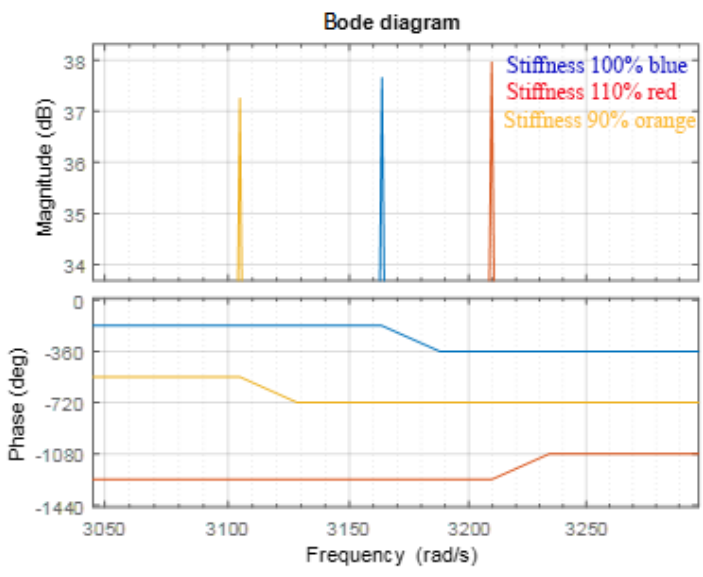

Fig. (11): The enlargement of the second mode of the Bode diagram in Fig. (10)

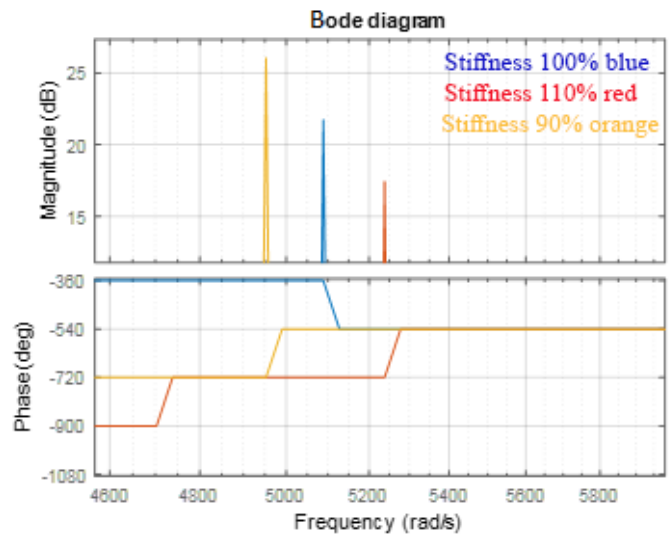

Fig. (12): The enlargement of the fourth mode of the Bode diagram in Fig. (10)

The bode diagram of the dynamic system based on different values of torsional stiffness of the ball screw is shown in Fig. (13). The three different values of torsional stiffness of the ball screw are $110 \%, 100 \%$ and $90 \%$ of the value of the rated torsional stiffness of the ball screw which its value equal to $496.7 \mathrm{~N} . \mathrm{m} / \mathrm{rad}$ as shown in table (1). So the three different torsional stiffness of the ball screw are 546.37 N.m/rad, 496.7 N.m/rad and 447.03 N.m/rad respectively.

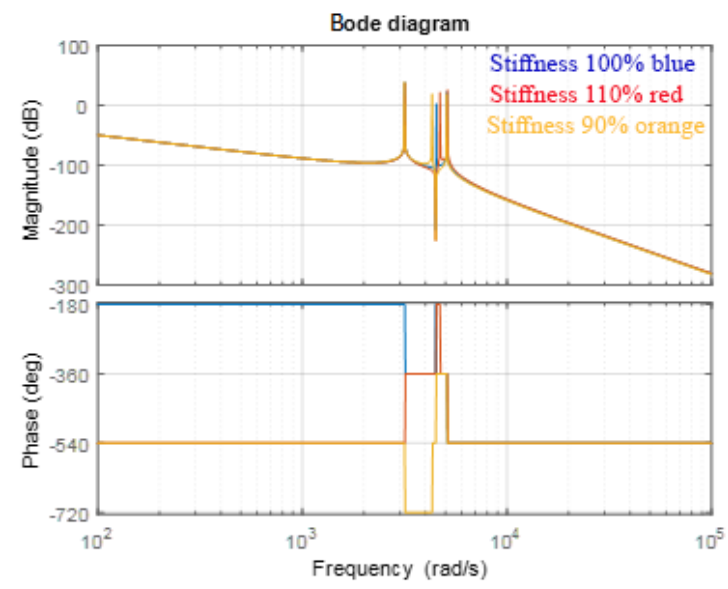

Fig. (13): Bode diagram of torsional stiffness of the ball screw 


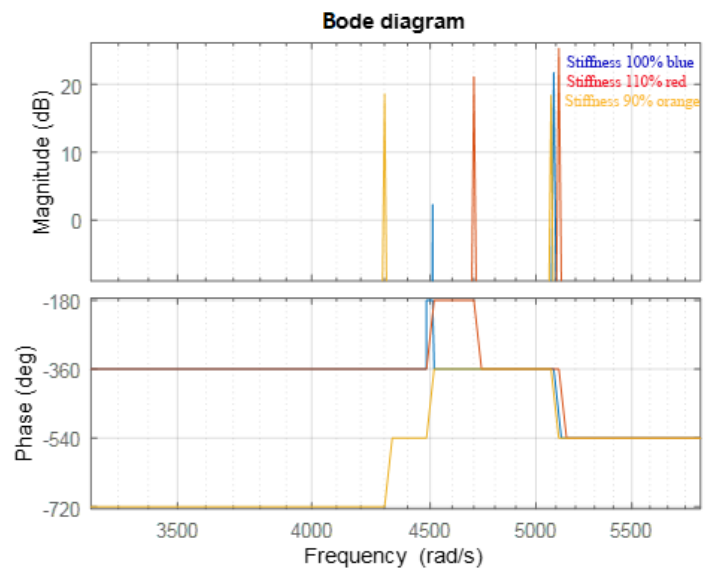

Fig. (14): The enlargement of the third mode of the Bode diagram in Fig. (13)

\section{DisCUSSION OF RESUlts}

Enlargement of the second and fourth modes of the bode diagram are shown in Figures (5\&6). The frequency change in the first and third modes is very small. In second mode the frequency changes from $3.1636 \times 10^{3} \mathrm{~Hz}$ to $3.04 \times 10^{3} \mathrm{~Hz}$ in case of increase table mass by $10 \%$, and to $3.3 \times 10^{3} \mathrm{~Hz}$ in case of decreasing table mass by $10 \%$. In fourth mode the frequency changes from $5.0886 \times 10^{3} \mathrm{~Hz}$ to $5.05 \times 10^{3} \mathrm{~Hz}$ in case of increasing table mass by $10 \%$, and to $5.14 \times 10^{3} \mathrm{~Hz}$ in case of decrease table mass by $10 \%$. It is obvious that the second and fourth modes will be affected more than other modes when the mass table is varying.

As expected when the mass of table increase the vibration fundamental frequency decreased because the frequency is inversely proportional to the mass (frequency $\propto 1 / \mathrm{mass}$ ) so when the mass of table increased by $10 \%$ we noticed that the frequency decreased. And vice versa when mass of table decreased by $10 \%$ the frequency increased.

Enlargement of the second and fourth modes of the bode diagram are shown in Figures $(8 \& 9)$. In second mode the frequency changes from $3.1636 \times 10^{3} \mathrm{~Hz}$ to $3.26 \times 10^{3} \mathrm{~Hz}$ in case of increase stiffness of the ball nut by $10 \%$, and to $3.05 \times 10^{3} \mathrm{~Hz}$ in case of decrease stiffness of the ball nut by $10 \%$. In fourth mode the frequency changes from $5.0886 \times 10^{3} \mathrm{~Hz}$ to $5.18 \times 10^{3}$ $\mathrm{Hz}$ in case of increase stiffness of the ball nut by $10 \%$, and to $5 \times 10^{3} \mathrm{~Hz}$ in case of decrease stiffness of the ball nut by $10 \%$.

Enlargement of the second and fourth modes of the bode diagram are shown in Figures $(11 \& 12)$. In second mode the frequency changes from $3.1636 \times 10^{3} \mathrm{~Hz}$ to $3.21 \times 10^{3} \mathrm{~Hz}$ in case of increase axial stiffness of the ball screw shaft by $10 \%$, and to $3.1 \times 10^{3} \mathrm{~Hz}$ in case of decrease axial stiffness of the ball screw shaft by $10 \%$. In fourth mode the frequency changes from $5.0886 \times 10^{3} \mathrm{~Hz}$ to $5.24 \times 10^{3} \mathrm{~Hz}$ in case of increase axial stiffness of the ball screw shaft by $10 \%$, and to $4.95 \times 10^{3} \mathrm{~Hz}$ in case of decrease axial stiffness of the ball screw shaft by $10 \%$.

Enlargement of third mode of the bode diagram shown in Fig. (14). The frequency change in the first and second modes is very small. In third mode the frequency changes from $4.5115 \times 10^{3} \mathrm{~Hz}$ to $4.7 \times 10^{3} \mathrm{~Hz}$ in case of increase torsional stiffness of the ball screw by $10 \%$, and to $4.3 \times 10^{3} \mathrm{~Hz}$ in case of decrease torsional stiffness of the ball screw by $10 \%$.

The frequency of the system increases with increasing the stiffness because the relation between them is $\omega 2=\mathrm{k} / \mathrm{m}$ where $\omega$ the natural frequency, $\mathrm{k}$ stiffness, $\mathrm{m}$ mass. So the frequency is directly proportional to the stiffness (frequency $\propto$ stiffness). As shown in results, with increasing the stiffness of nut or torsional stiffness of ball screw or axial stiffness of ball screw the frequency of the system increase.

The frequency of the system increases with increasing the stiffness of nut or the torsional stiffness of ball screw or the axial stiffness of ball screw as shown in the previous results because the relation between them is $\omega^{2}=\mathrm{k} / \mathrm{m}$ where $\omega$ the natural frequency, $\mathrm{k}$ stiffness, $\mathrm{m}$ mass.

\section{CONCLUSION}

The change in displacements arrangement of the system cause change in both phase angles and chart trend while the frequencies still the same.

The numerical simulation of a lumped parameter model by using different values of table mass, stiffness of the ball nut, axial stiffness of the ball screw shaft and torsional stiffness of the ball screw describe changes in dynamic behavior of the system. Effects of each parameter in this model can be diagnosed by determining the change in value of frequency peaks.

The inertia moment of both the motor and ball screw system did not have any significant effect in the system performance.

When changing by increasing or decreasing the values of the investigated parameters, the rotation displacement of the ball screw and the axial displacement of the working table have the biggest effect more than other states.

\section{REFERENCE}

[1] Altintas Y., Verl A., Brecher C., Uriarte L., Pritschow G. (2011). Machine Tool Feed Drives. CIRP Annals 60(2), (pp.779-796).

[2] Wenjing Jin, Yan Chen, Jay Lee. (2013). Methodology for Ball Screw Component Health Assessment and Failure Analysis. International Manufacturing Science 


\section{International Journal of Engineering Applied Sciences and Technology, 2020 \\ Vol. 5, Issue 8, ISSN No. 2455-2143, Pages 28-35 \\ Published Online December 2020 in IJEAST (http://www.ijeast.com)}

and Engineering Conference, DOI: 10.1115/MSEC20131252.

[3] Liang Luo, Weimin Zhang. (2018). Electromechanical Co-Simulation for Ball Screw Feed Drive System. New Trends in Industrial Automation, IntechOpen, DOI: 10.5772/intechopen.80716.

[4] Huang Y.C., Chen X.Y. (2017). Investigation of a Ball Screw Feed Drive System Based on Dynamic Modeling for Motion Control. Adv. technol. innov., vol. 2, no. 2, (pp. 29-33).

[5] Christian Brecher, Bastian Eßer, Jens Falker, Florian Kneer, Marcel Fey. (2018). Modelling of ball screw drives rolling element contact characteristics. CIRP Annals 67(1), manufacturing technology, (pp. 409-412).

[6] Liang Dong, WenCheng Tang. (2013). Hybrid modeling and analysis of structural dynamic of a ball screw feed drive system. Mechanika, Volume 19(3), (pp.316-323).

[7] Okwudire C.E., Altintas Y. (2009). Hybrid Modeling of Ball Screw Drives With Coupled Axial, Torsional, and Lateral Dynamics. Journal of Mechanical Design 131(7), (pp. 1-9).

[8] Holroyd G., Pislaru C. , Ford D.G. (2003). Modelling the dynamic behaviour of a ballscrew system taking into account the changing position of the ball-screw nut. WIT Transactions on Engineering Sciences, volume 44, DOI: 10.2495/LAMDAMAP030291

[9] Zaeh M.F. , Oertli Th. , Milbergb J. (2004). Finite Element Modelling of Ball Screw Feed Drive Systems. CIRP Annals 53(1), (pp.289-292).

[10] Frey S. , Dadalau A. , Verl A. (2012). Expedient modeling of ball screw feed drives. Prod. Eng. Res. Devel. 6, (pp.205-211).

[11] Erkorkmaz K., Kamalazadeh A. (2006). High bandwidth control of ball screw drives. CIRP Annals 55(1), (pp.393398).

[12] Van Brussel H., Van Den Braembussche P. (1998). Robust Control of Feed Drives with Linear Motors. CIRP Annals 47(1), (pp.325-328). 